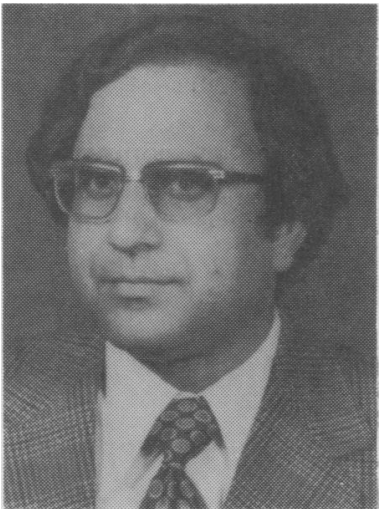

D. N. Mathur

\section{AGE AT MENARCHE IN NIGERIAN ATHLETES}

D. N. MATHUR, MD and Abel L. TORIOLA, BSc

Institute of Physical Education, University of Ife, Nigeria

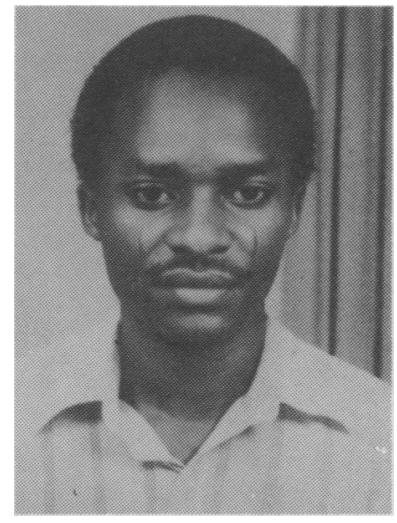

Abel L. Toriola

\title{
ABSTRACT
}

The subjects of the study were $\mathbf{4 1 8}$ highly successful female athletes and $\mathbf{5 1 2}$ female non-athletes drawn from all over Nigeria. Recall procedures were used to ascertain the age at menarche. The study gave the following results: In general, over-all mean menarcheal age of athletes $(14.13$ years) was significantly higher $(p<.05)$ than that of non-athletes (13.57 years). Menarche was significantly $(p<.05)$ delayed $(14.41$ years) in those athletes $(n=272)$ who started physical activities before the onset of menstruation. The mean menarcheal age of non-athletes i.e. general population was significantly lower $(p<.05)$ than that established thirty years ago in Nigerian women.

\section{INTRODUCTION}

The onset of menstruation is an important index of growth and development of women. According to Amudsen and Diers (1969), age of menarche in the classical period was, most probably, around 13-14 years. Damon et al (1969) and Huber (1973) agreed that menarcheal age varies from one country to another and is influenced by genetic, socio-economic and climatic factors. Ellis (1950) observed that in tropical countries such as Nigeria, the mean age at menarche was significantly delayed (14.22 years) as compared with that of Great Britain (13.73 years). The age at menarche may be different in athletes and non-athletes. Malina et al (1973) found that mean age at menarche for athletes was significantly higher (13.58 years) as compared to that of a control group (12.23 years). Further, Malina et al (1978) noted that college athletes attained menarche significantly later than non-athletes and various groups of national and Olympic athletes attained menarche significantly later than high school and college athletes. Sidhu and Grewal (1980) observed a significant difference between the mean age at menarche in Indian sportswomen (15.21 years) and control samples (14.05 years). These studies substantiate the findings of Malina et al (1978) that there is a possibility of different maturity relationships for different sports and competitive levels among women athletes of different countries.

In this study, an attempt has been made to determine whether menarcheal age of Nigerian women athletes differs from that of non-athletes. This would afford an understanding of the probable influence of physical exercise on the menarcheal age. Also, a comparative analysis of mean menarcheal ages of a general population now and three decades ago would be useful to assess the effect of improved socio-economic status on puberty.

\section{MATERIALS AND METHODS}

Subjects of the study were $\mathbf{4 1 8}$ women athletes and $\mathbf{5 1 2}$ women non-athletes drawn from all over Nigeria. The athletes were successful performers at the 1981 National Sports Festival held at Benin City, Nigeria. Questionnaires were designed to seek information concerning their age at menarche and the age at which they started regular participation in sports. The procedures as suggested by Damon et al (1969) and validated by Damon and Bajema (1974) were considered in determining the subjects' recalled age at menarche. For the purpose of the study and analysis of data the following four groups were constituted:

Group A: Control subjects (non-athletes)

Group B: Combined samples of athletes

Group C: Athletes with regular sports participation starting before menarche

Group D: Athletes with regular sports participation only after menarche 
The test for significance in the difference between the means of various groups was calculated by using a ' $t$ ' test.

\section{TABLE I}

Mean age at menarche in various groups

\begin{tabular}{|c|c|c|c|c|}
\hline Category & $\mathbf{n}$ & $\begin{array}{c}\text { Mean menarcheal } \\
\text { Age (Years) }\end{array}$ & S.D. & 't' value \\
\hline $\begin{array}{l}\text { Control sample } \\
\text { (Group A) }\end{array}$ & 512 & 13.57 & 1.52 & \\
\hline $\begin{array}{l}\text { Combined sample of } \\
\text { Athletes (Group B) }\end{array}$ & 418 & 14.13 & 1.59 & $p<\begin{array}{l}5.45^{a} \\
0.05\end{array}$ \\
\hline $\begin{array}{l}\text { Athletes before } \\
\text { menarche (Group C) }\end{array}$ & 272 & 14.41 & 1.67 & $p<0.05$ \\
\hline $\begin{array}{l}\text { Athletes after } \\
\text { menarche (Group D) }\end{array}$ & 146 & 13.53 & 1.63 & $\begin{array}{l}0.27^{C} \\
\text { NS }\end{array}$ \\
\hline
\end{tabular}

\section{RESULTS AND DISCUSSION}

The mean menarcheal age of combined samples of athletes (Group B) was higher (14.13 years) than that of non-athletes (13.57 years). The ' $t$ ' value between the two groups was 5.45. The mean menarcheal age of athletes who started participation in sports before menarche (Group C) was further delayed (14.41 years). The ' $t$ ' value between Group $C$ and control samples was 6.91 (Table 1). Both the differences were significant at .05 level. No significant difference between the mean ages of menarche in Group $D$ and control samples could be noted (Table I). It seems most probably that menarche is delayed under the influence of regular sports activities. This confirms the findings of Malina et al (1973) and Sidhu and Grewal (1980).

It is obvious from Table II that with the exception of jumpers, athletes of different activity groups in Group $C$ had significantly delayed onset of menstruation, expecially ball game players and throwers. It is possible that they were subjected to more strenuous physical exercises. Contrary to the findings of Astrand ot al (1963), the swimmers in this study had a delayed onset (14.28 years) as compared to that of control subjects.

According to Fox and Mathews (1981), late maturation in women is advantageous for successful athletic performance. It was noted that a majority of successful athletes in this study ( $n=272$ or $65.07 \%$ ) commenced their sports activities before the onset of menstruation. This may also explain the assertion of Malina et al (1978) that women who mature late are more successful performers.

The findings of this study support the general trend of younger menarcheal age as a result of socio-economic development. Ellis (1950) had investigated the age at menarche in Nigerian women $(n=300)$ in 1950 which was then 14.22 years. In the present study, the mean age of menarche of non-athletes or in other words the general population $(n=512)$ was 13.57 years. It is believed that the lowering of mean age at menarche of Nigerian women may be due to considerable sociooconomic transformation that has taken place in Nigeria since 1950. This also confirms the findings of Lee et al (1963) and Zacharias et al (1970) who observed an accelerating influence of good nutrition and improved socio-economic status on puberty.

\section{TABLE II}

Mean age of menarche in different activity groups

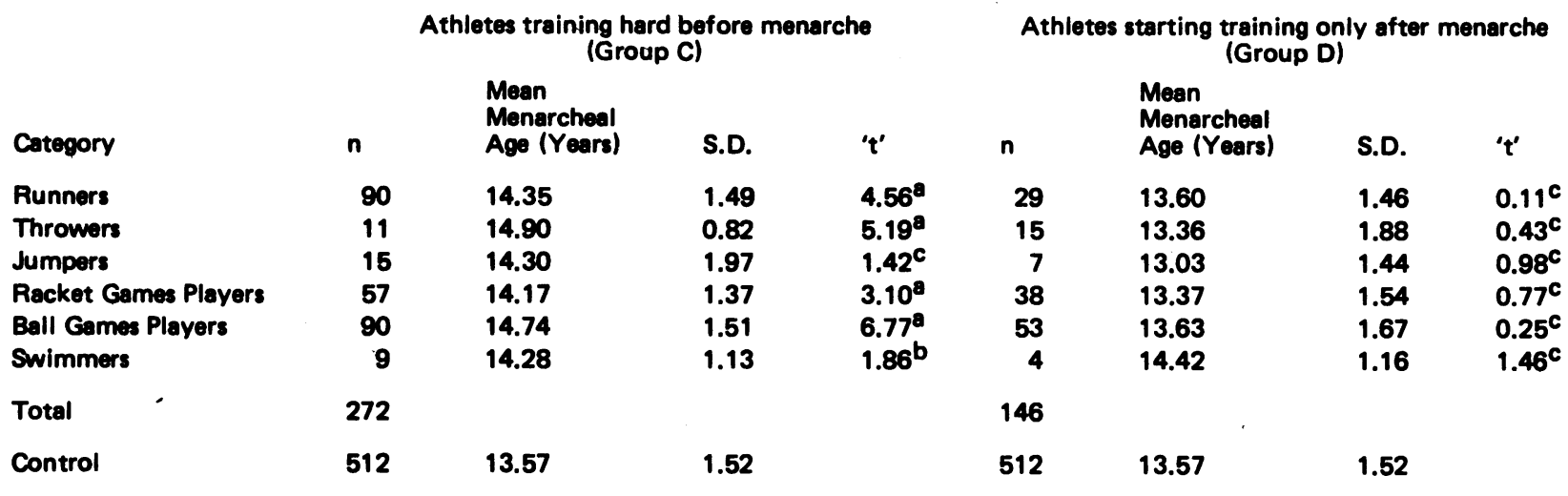

a significant $(p<0.05)$

b significant $(p<0.10)$

c insignificant 


\section{REFERENCES}

Amudsen, D. N. and Diers, C. J., 1969 "The age of menarche in classical Greece and Rome". Human Biol. 41: $125-132$.

Åstrand, P. O., Eriksson, B. O., Nylander, I., Engstrom, L., Karlberg, P., Saltin, B. and Thoren, C., 1963 “Girl swimmers". Acta Paediat., Supplement, 147.

Damon, A., Damon, S. T., Reed, R. B. and Valadian, I., 1969 "Age at menarche of mothers and daughters, with a note on accuracy of recall". Human Biol. 41: 161-175.

Damon, A. and Bajema, C. J., 1974 "Age at menarche: Accuracy of recall after thirty-nine years". Human Biol. 46: 381-384.

Ellis, W. B., 1950 "Age of puberty in tropics". Brit.Med.J. 1: 85-88.

Fox, L. E. and Mathews, D. K., 1981. The Physiological Basis of Physical Education and Athletics. Saunders College Publishing, Philaddphia.

Huber, A., 1973 "Zur akzeleration des menarchealters". Wiener Klinsche Wochenschrift 81: 844-847.

Lee, M. M. C., Chang, K. S. F. and Chan, M. M. C., 1963 "Sexual maturation of Chinese girls in Hong Kong". Paediatrics 32: 300-393.

Malina, R. M., Harper, A. B., Auent, H. H. and Campbell, D. E., 1973 "Age at menarche in athletes and non-athletes". Med.Sci.Sports 5: 11-13.

Malina, R. M., Spirduso, W. W., Tate, C. and Baylor, A. M., 1978 "Age at menarche and selected menstrual characteristics in athletes at different competitive levels and different sports". Med.Sci.Sports 10: 218-222.

Sidhu, L. S. and Grewal, R., 1980 "Age of menarche in various categories of Indian sportswomen". Brit.J.Sports Med. 14: 199-203.

Zacharias, L., Wurtman, R. J. and Schatzoff, M., 1970 "Sexual maturation in contemporary American girls". Amer.J. Obstet.Gynae. 108: 833-846.

\section{BOOK REVIEW}

Title: $\quad$ SPORT IN SOCIETY - ISSUES AND CONTROVERSY 2nd EDITION

Editor: $\quad$ Jay J. Coakley, PhD, Professor of Sociology, University of Colorado, Colorado Springs

Publisher: $\quad$ C. V. Mosby Company, St. Louis - Toronto - London

Price $£ 10$

This book deliberately raises many controversial aspects of sport, and as such is of interest. Even though it mainly relates to sporting activities within the United States readers will find parallelism with situations existent in the Universal sporting environment. Items discussed include competition, aggression, children and females in sport, and the opportunities for inter-racial contact.

Each of these subjects is treated analytically. As an individual, I have enjoyed its pages but I feel its rightful place is the college library. Students in difficulty might from this book germinate ideas for projects or theses, a task which to some appears insurmountable.

Noel Bleasdale 